\title{
Prolyl isomerase Pin I is highly expressed in Her2-positive breast cancer and regulates erbB2 protein stability
} Prudence B Lam ${ }^{1,2}$, Laura N Burga ${ }^{1}$, Bryan P Wu ${ }^{1}$, Erin W Hofstatter ${ }^{1}$, Kun Ping Lu${ }^{1}$ and Gerburg M Wulf*1

Address: ${ }^{1}$ Cancer Biology Program, Division of Hematology/Oncology, Department of Medicine, Beth Israel Deaconess Medical Center, Harvard Medical School, 330 Brookline Avenue, NRB 1030c, Boston, MA 02215, USA and 2Cambridge Health Alliance, 1439 Cambridge St, Cambridge, MA 02139, USA

Email: Prudence B Lam - plam@challiance.org; Laura N Burga - lburga@bidmc.harvard.edu; Bryan P Wu - bwu@bidmc.harvard.edu; Erin W Hofstatter - ehofstatter@bidmc.harvard.edu; Kun Ping Lu - klu@bidmc.harvard.edu; Gerburg M Wulf* - gwulf@bidmc.harvard.edu

* Corresponding author

Published: 15 December 2008

Molecular Cancer 2008, 7:91 doi:10.1186/|476-4598-7-91
Received: 24 June 2008

Accepted: 15 December 2008

This article is available from: http://www.molecular-cancer.com/content/7/I/91

(C) 2008 Lam et al; licensee BioMed Central Ltd.

This is an Open Access article distributed under the terms of the Creative Commons Attribution License (http://creativecommons.org/licenses/by/2.0), which permits unrestricted use, distribution, and reproduction in any medium, provided the original work is properly cited.

\begin{abstract}
Overexpression of HER-2/Neu occurs in about $25-30 \%$ of breast cancer patients and is indicative of poor prognosis. While Her2/Neu overexpression is primarily a result of erbB2 amplification, it has recently been recognized that erbB2 levels are also regulated on the protein level. However, factors that regulate Her2/Neu protein stability are less well understood. The prolyl isomerase Pin I catalyzes the isomerization of specific pSer/Thr-Pro motifs that have been phosphorylated in response to mitogenic signaling. We have previously reported that Pinl-catalyzed postphosphorylational modification of signal transduction modulates the oncogenic pathways downstream from c-neu. The goal of this study was to examine the expression of prolyl isomerase Pin I in human Her2+ breast cancer, and to study if Pin I affects the expression of Her2/Neu itself.

Methods: Immunohistochemistry for Her2 and Pinl were performed on two hundred twentythree human breast cancers, with $59 \%$ of the specimen from primary cancers and $41 \%$ from metastatic sites. Pin I inhibition was achieved using siRNA in Her2+ breast cancer cell lines, and its effects were studied using cell viability assays, immunoblotting and immunofluorescence.
\end{abstract}

Results: Sixty-four samples (28.7\%) stained positive for Her2 (IHC 3+), and 54\% (I22/223) of all breast cancers stained positive for Pin I. Of the Her2-positive cancers 40 (62.5\%) were also Pin Ipositive, based on strong nuclear or nuclear and cytoplasmic staining. Inhibition of Pin I via RNAi resulted in significant suppression of Her2-positive tumor cell growth in BT474, SKBR3 and AU565 cells. Pin I inhibition greatly increased the sensitivity of Her2-positive breast cancer cells to the mTOR inhibitor Rapamycin, while it did not increase their sensitivity to Trastuzumab, suggesting that Pin I might act on Her2 signaling. We found that Pin I interacted with the protein complex that contains ubiquitinated erbB2 and that Pin I inhibition accelerated erbB2 degradation, which could be prevented by treatments with the proteasome inhibitor ALLnL.

Conclusion: Pin I is a novel regulator of erbB2 that modulates the ubiquitin-mediated degradation of erbB2. The overexpression of Pinl in a majority of Her2-overexpressing breast cancer may contribute to maintain erbB2 levels. Pin I inhibition alone and in conjunction with mTOR inhibition suppresses the growth of Her2+ breast cancer cells. 


\section{Background}

Overexpression of the receptor tyrosine kinase HER-2/ Neu occurs in up to $30 \%$ of breast cancer patients and is indicative of poor prognosis [1]. Her2/Neu plays an important causal role in breast carcinogenesis, and serves as a therapeutic target for the humanized monoclonal antibody Trastuzumab (Herceptin) [2,3]. While Her2Neu overexpression is primarily a result of erbB2 amplification, it has recently been recognized that erbB2 levels are also regulated on the protein level $[4,5]$. However, factors that regulate Her2/Neu protein stability are less well understood. The prolyl isomerase Pin 1 catalyzes the isomerization of specific pSer/Thr-Pro motifs that have been phosphorylated in response to mitogenic signaling. This post-phosphorylational modification can have profound effects on the stability, function and localization of the target protein $[6,7]$ Pin 1 is overexpressed in a range of human cancers $[8,9]$, and high Pin 1 expression is found in common adenocarcinomas, such as breast, lung, colon and prostate cancers $[10,11]$. In breast cancer, Pin 1 levels are increased more in high grade than in low grade tumors [8]. A similar trend was found in prostate cancer. Ayala et al examined Pin 1 levels in prostatectomy specimens from 580 prostate cancer patients and found a tight correlation of high Pin1 levels with poor prognosis [10]. Increased Pin1 levels were highly predictive of clinical failure, i.e. the development of metastatic disease in men who had undergone prostatectomy. In pre-clinical studies, Ryo et al. showed that siRNA inhibition of Pin 1 inhibited both the growth of prostate cancer cell lines in vitro, and the outgrowth of prostate cancers in mouse xenotransplant experiments [12]. The association of Pin 1 with an aggressive biology in both prostate and breast cancers points toward a potential tumor-promoting function of Pin1.

On the molecular level, Pin1-mediated prolyl isomerization can regulate its targets by either affecting their transcription, their stability or their function, depending on its target. Pin 1 typically binds phospho-serine or phospho-threonine residues next to Proline. Upon binding with its WW-domain, Pin 1 catalyzes the conversion of the adjacent prolyl residue from the cis to the trans position or vice versa. This post-phosphorylational conformational change can have profound impacts on the function, subcellular localization or stability of the target protein. Pin 1 modulates several proteins that are activated downstream from erbB2, such as the AP1 complex members cjun [8] and c-fos and cyclin D1 $[13,14]$. Pin 1 regulates the phosphorylation status of Raf- 1 kinase through regulation of the interaction with its phosphatase, PP2A. Raf- 1 is responsive to receptor tyrosine kinase activation, and upon phosphorylation Raf-1 activates MEK and ERK kinases [15]. Pin1 mediated-prolyl isomerization augments various molecular functions, such as the transcriptional activity of c-fos [16]or c-jun[8,17], the localization and stability of cyclinD1[8,14,18-20] or the de-phosphorylation of Raf-1[15]. The net result of the diverse effects of Pin1-mediated prolyl isomerization of these mitotic phosphoproteins downstream from erbB2 is always accelerated progression through mitosis and cell growth.

We therefore hypothesized that inhibition of Pin 1 might block the growth of Her2-positive breast cancer cells. We have previously shown that Pin 1 null mice were largely protected from breast cancers induced by the c-neu transgene [13]. While $100 \%$ of the MMTV-Ras and over $90 \%$ of the MMTV-Neu transgenic mice in the wild-type Pin 1 background developed one or several breast cancers within 75 weeks of observation, over $85 \%$ of transgenic mice in the Pin 1 -/- background remained breast cancerfree over the same period. These in vitro and in vivo data point toward Pin 1 as a potential therapeutic target in adenocarcinomas, and specifically Her2+ breast cancer [13]. However, although these studies showed that the absence of Pin 1 prevented breast cancer induced by Her 2 or Ras, they have not demonstrated that Pin 1 inhibition can successfully treat breast cancer. Here, we report that Pin 1 overexpression is found in $62 \%$ of Her2-positive breast cancer, and that Pin 1 inhibition suppresses the growth of Her2-positive breast cancer cells. While Pin1-inhibition greatly increased the sensitivity of Her2-positive breast cancer cells to the mTOR inhibitor Rapamycin, it did not increase their sensitivity to Trastuzumab. Instead, Pin1inhibition interfered with erbB2 signaling by decreasing erbB2 protein levels through an acceleration of erbB2 degradation.

\section{Materials and methods Materials}

Breast cancer cell lines were purchased from the American Type Culture Collection (ATCC) and maintained in DMEM supplemented with 10\% fetal bovine serum. Trastuzumab(Genentech, San Francisco) was obtained from our pharmacy. Rapamycin was from Signal Transduction Laboratories. Anonymized tissue microarrays with corresponding diagnostic information were purchased from Immunogenex. Anti-HER2 (Ab-1 and Ab-3) were obtained from Calbiochem. Actin antibodies and Cycloheximide were from Sigma. cDNA Synthesis was done using a reverse transcriptase kit from Roche (Indianapolis, IN). Vector control and DN-Pin1 (S16A) mutation under the control of the $\mathrm{CMV}$ promoter have been described previously [8].

\section{siRNA}

Pin 1 siRNA duplexes were purchased from and designed by Qiagen using the HiPerformance Design Algorithm licensed from Novartis. Additional siRNA duplexes directed against three other regions of the Pin 1 mRNA were purchased from Invitrogen. All siRNAs led to a 
down-regulation of Pin 1 , the most effective inhibition was achieved with the target sequence CAG GCC GAG TGT ACT ACT TCA. A scrambled siRNA was used as a negative control. HiPerfect Reagent was from Quiagen and used with Opti-MEM according to manufacturer's instructions.

\section{Immunoblotting, RNA extraction, and immunofluorescence were done as described [13]}

Immunofluorescence images were obtained using a Zeiss Confocal Laser Microscope LSM 510.

\section{Cell viability assay}

The Promega Cell-Titer Blue Viability Assay was used to assess cell viability at the indicated time points. Cells were grown in 96-well plates and the assay performed according to the manufacturer's instructions. Absorption was read in a Perkin Elmer spectrophotometer with plate reader.

\section{Immunohistochemistry}

Her2/neu-positive human breast cancer tissue and control slides were obtained from Zymed Laboratories (S. San Francisco, CA). Additional slides and tissue were also purchased from Tissue Array Networks. The HercepTest from DakoCytomation was used to stain for Her2, per the included protocol. Scoring was done blinded by a pathologist (BW).

\section{Results \\ Pin I is overexpressed in $62 \%$ of Her2-amplified breast cancer}

As a first step, we set out to examine the frequency of Pin 1 overexpression in Her2+ human breast cancer. A total of 223 breast cancer specimens, mostly from primary tumors, were analyzed by immunohistochemistry for Her 2 and Pin 1 expression. The intensity and distribution of the stain were graded (Tab 1). Fig. 1 provides examples of the IHC stains for Her2 (upper panels) and Pin 1 (lower panels). Both stains were specific for the epithelial cancer cells with little or no no background stain in the architectural and connective tissue portions of the specimen. Cells were considered Her2-positive (3+) when a strong stain encircled the entire cell. Weak and incomplete staining were graded $1+$ or $2+$ and absent staining 0 . Her $21+, 2+$ and 0 were considered negative. Pin 1 staining was also graded according to intensity $(0-3+)$. In most cancers we found nuclear and cytoplasmic localization of Pin1; however, in some cancers we saw only nuclear staining. Pin 1 has been found in both nucleus and cytoplasm in cancer cells $[8,10,21]$, and it is at this point unclear what biological significance a variation in the subcellular distribution of Pin 1 may have. We found that $54 \%$ of all breast cancers
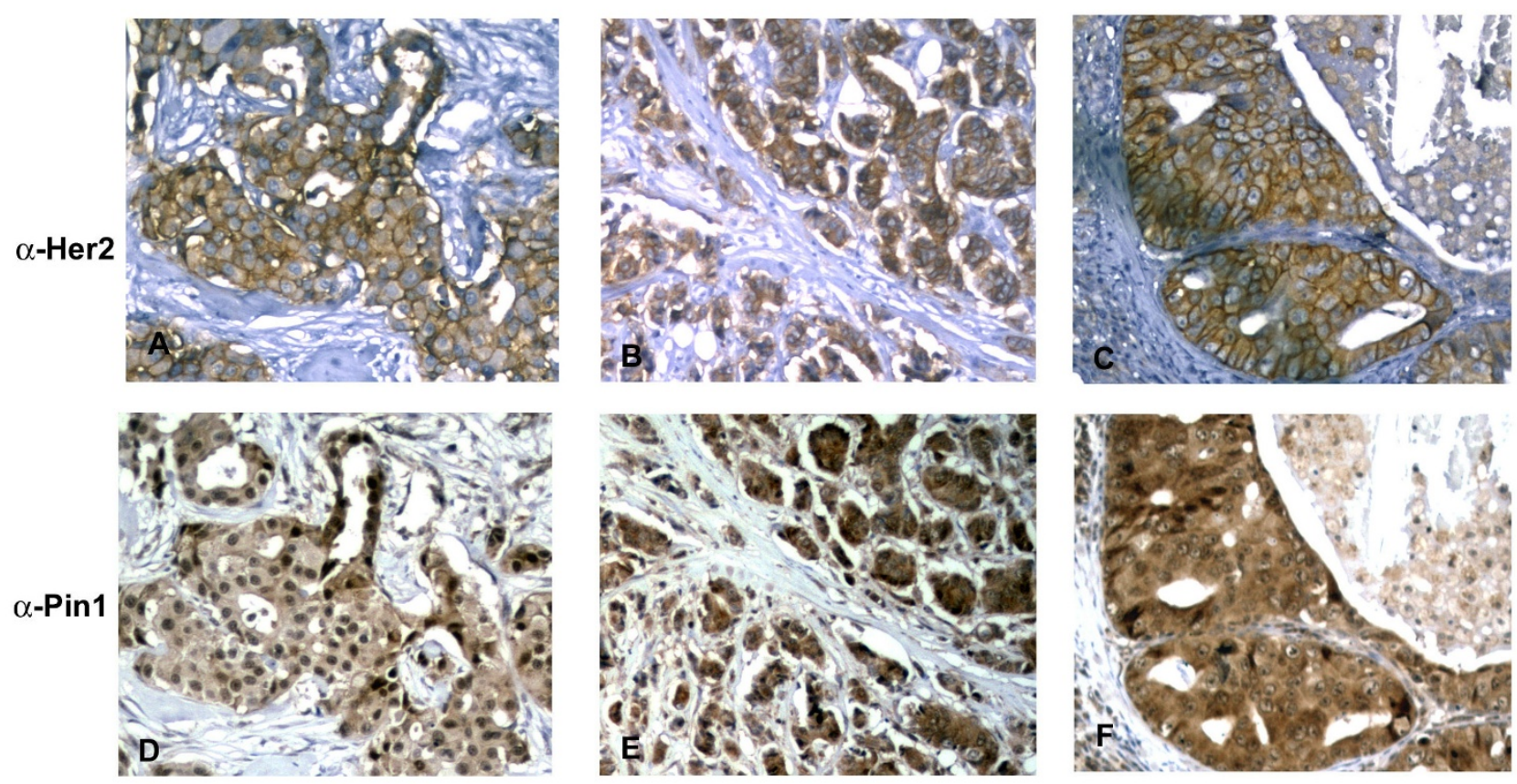

\section{Figure I}

Examples of immunohistochemistry stains for Pin I and Her2 on 3 individual tumors (in rows A through $F$ ), IHC for Her2 (A, B, C) and Pin I (D, E, F) performed using standard procedures on consecutive slides. 
Table I: Correlation of Pin I and Her2 stains in breast cancer. 64/ $223(28.7 \%)$ of samples were Her2-positive (3+ index). $122 / 223$ (54\%) were Pin I + (3+ index), 40/64 (62.5\%) of Her2+ breast cancer were also Pin I+.

\begin{tabular}{llllll}
\hline & Her - & Her2 I+ & Her2 2+ & Her2 3+ (pos) & \\
\hline Pin I & 43 & 9 & 10 & 21 & 83 \\
\hline $1+$ & 0 & 1 & 0 & 1 & 2 \\
\hline $2+$ & 8 & 4 & 2 & 2 & 16 \\
\hline $3+$ (pos) & 63 & 13 & 6 & 40 & 122 \\
\hline & 114 & 27 & 18 & 64 & 223 \\
\hline
\end{tabular}

were Pin1-positive (Tab. 1). $28.7 \%$ of the breast cancers were Her2-positive, which is consistent with literature reports ([22-24]), and amongst the samples that were Her2-positive in our cohort, $62.5 \%$ were also Pin $1+$. In summary, a majority of breast cancers overexpressed Pin 1 (54\%), and Pin1 overexpression was more prevalent in Her2-overexpressing tumors (62.5\%) than in Her2-negative breast cancers. (Tab. 1). This observation led us to the question whether Pin 1 inhibition would affect the growth of Her2+ breast cancer cells.

\section{Pin I inhibition suppresses the growth of Her2+ breast cancer cells}

The expectation that Pin 1 inhibition might suppress the growth of Her2+ breast cancer cells is based on the following pre-clinical observations: 1 . Pin 1 -/- mice are largely protected from breast cancers induced by the c-neu transgene [13]. 2. Pin1 is a pivotal regulator of cyclin D1 expression $[7,8,13,14,25]$, and disruption of the cyclin D1 gene in mice also suppresses the ability of the c-Neu transgene to induce tumor development in the mammary gland [26]. 3. Pin1 inhibition has previously been shown to inhibit MAPKinase signaling [27] and signaling downstream from Raf-kinase [15].

To inhibit Pin1, we optimized Pin1-specific siRNA transfection with a 20-mer directed against the 5' portion of Pin 1 and achieved near-complete ablation of Pin 1 in all breast cancer cell lines examined within 72 hours of transfection (Fig. 2, 3, 4A, B and Fig. 5).

To examine the effect of Pin 1 inhibition on the growth pattern of breast cancer with Her2-amplification, we used siRNA inhibition of Pin 1 in the Her2-positive cell lines AU565, BT474 and SKBr3. We plated these cells on day 3 after transfection at equal densities. After 4 more days, viability was assessed using the MTT assay, continued Pin1 inhibition was confirmed with immunoblotting. Consistent with prior reports, Pin1 inhibition slowed down cell growth considerably (Fig. 2). Within 4 days in culture, control-transfected cells grew exponentially, while the Pin 1 si-RNA treated cells grew very slowly (Fig. 2). In summary, Pin1-inhibition led to a consistent inhibition of cell growth in all three Her2-positive cell lines examined.

\section{Pin I inhibition enhances the growth-inhibitory effects of Rapamycin but not of Trastuzumab}

Resistance to erbB2-directed cancer treatments is an unsolved clinical problem $[28,29]$, and therefore we asked if Pin 1 inhibition could enhance the efficacy of other signaling inhibitors that target erbB2-dependent pathways. The monoclonal antibody Trastuzumab is FDA-approved for the treatment of breast cancer and inhibits the homodimerization of ErbB2 [28,30]. Rapamycin and its analogs, which are currently in late-stage clinical trials in breast cancer, inhibit mTOR kinase, a key regulator of cyclin D1 [31,32]. Both Trastuzumab and Rapamycin are clearly effective inhibitors of ErbB2-mediated signaling; however, they do not block breast cancer cell growth in vitro [29,33] or in vivo [30] completely but rather attenuate cancer cell growth. We therefore asked if Pin 1 inhibition could augment the efficacy of these drugs in vitro. We transfected AU565, BT474 and SKBr3 cells with control or Pin 1 siRNA, and after 3 days we seeded them out at equal densities and treated these cells with Trastuzumab and Rapamycin. After 4-7 more days, cell viability was assessed using the MTT assay, and the data were normalized to controls (vehicle-treated only). We found that the Her2+ cell lines AU565, BT474 and SKBR3 were modestly responsive to therapeutic doses of Trastuzumab in vitro at a range of $1-10 \mathrm{mcg} / \mathrm{ml}$ that correspond to therapeutic trough levels [34]. Unexpectedly, Pin1-inhibition did not increase the sensitivity of any of the Her2+ cell lines to Trastuzumab (Fig. 3A, B, C). Recently, concurrent Her2directed and mTOR-directed treatments have been proposed to overcome Trastuzumab sensitivity [35]. As reported earlier [36], the Her2+ cell lines were also sensitive to Rapamycin in the range of 1-10 nM. In contrast to Trastuzumab sensitivity, Rapamycin sensitivity increased substantially after Pin 1 inhibition (Fig. 3D, E, F), rendering the cells sensitive to doses as low as $0.1 \mathrm{nM}$ of the mTOR inhibitor. In summary, we found that Pin1-inhibition sensitized Her2-positive breast cancer cells to the mTOR-inhibitor Rapamycin, but not to the direct erbB2 inhibitor Trastuzumab.

\section{Pin I inhibition decreases erbB2 levels}

We then asked if Pin 1 affected components of the erbB2 signaling cascade other than cyclinD1, starting with erbB2 itself. Surprisingly, we found that Pin1-inhibition led to a decrease in erbB2 levels in all three Her2-positive cell lines starting 72 hours after Pin1 inhibition (Fig. 4 and 5). Immunoblotting showed near-complete ablation of Pin 1 after 72 hours (Fig. 4A, B, Fig. 5), with concomitant 


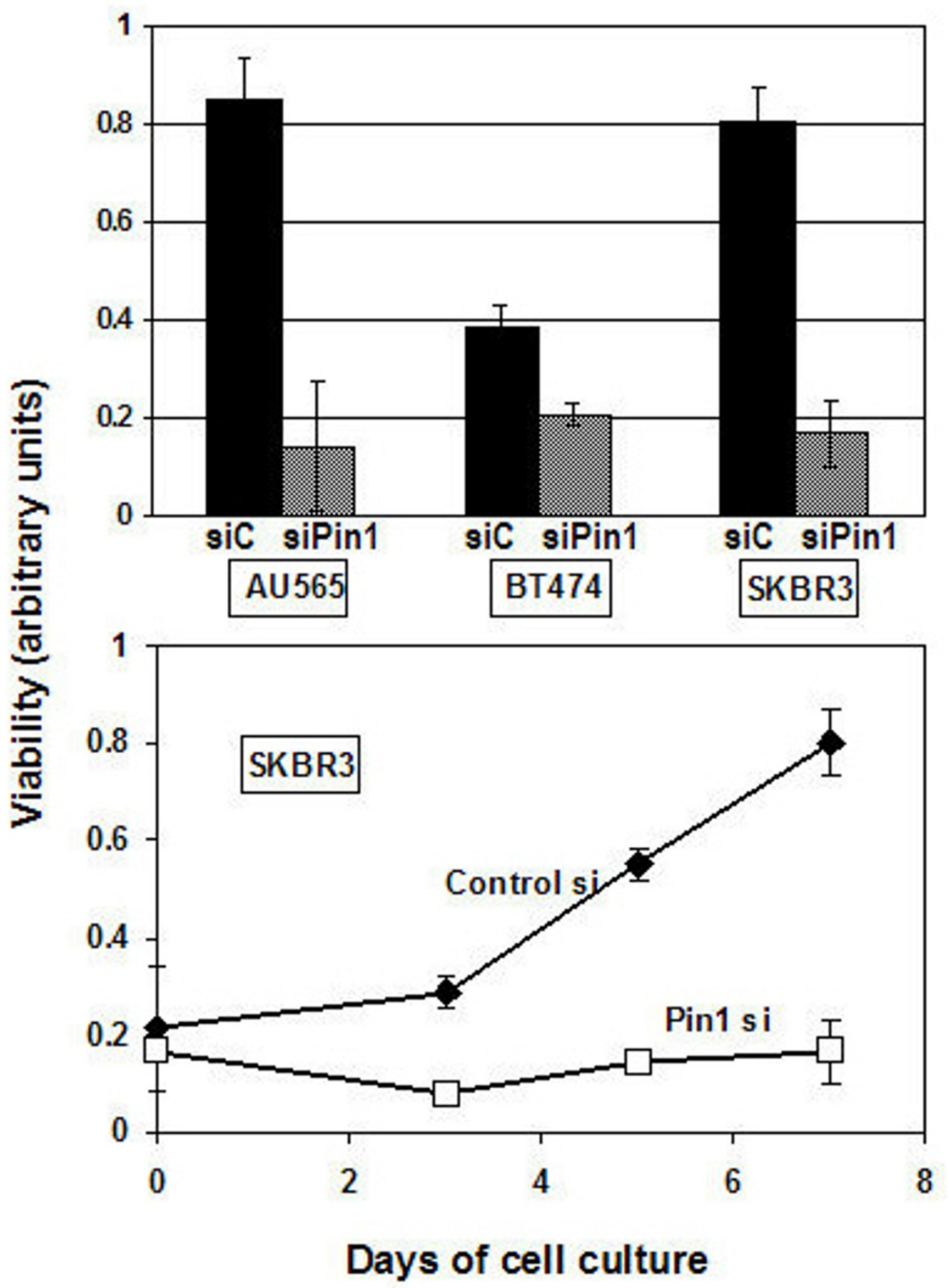

Figure 2

Pin I depletion inhibits the growth of Her2+ breast cancer cell lines. Cells were transfected with control RNAi (black bars) or Pin I siRNA (grey bars), and seeded on day 3 after transfection at 5000 cells/well in 96 -well plates. Cells were allowed to grow and the resulting cultures were subjected to an MTT-based viability assay and read in a 96 well reader after 7 days $(A)$ or at the indicated time points (B). Assays were done in triplicates. 

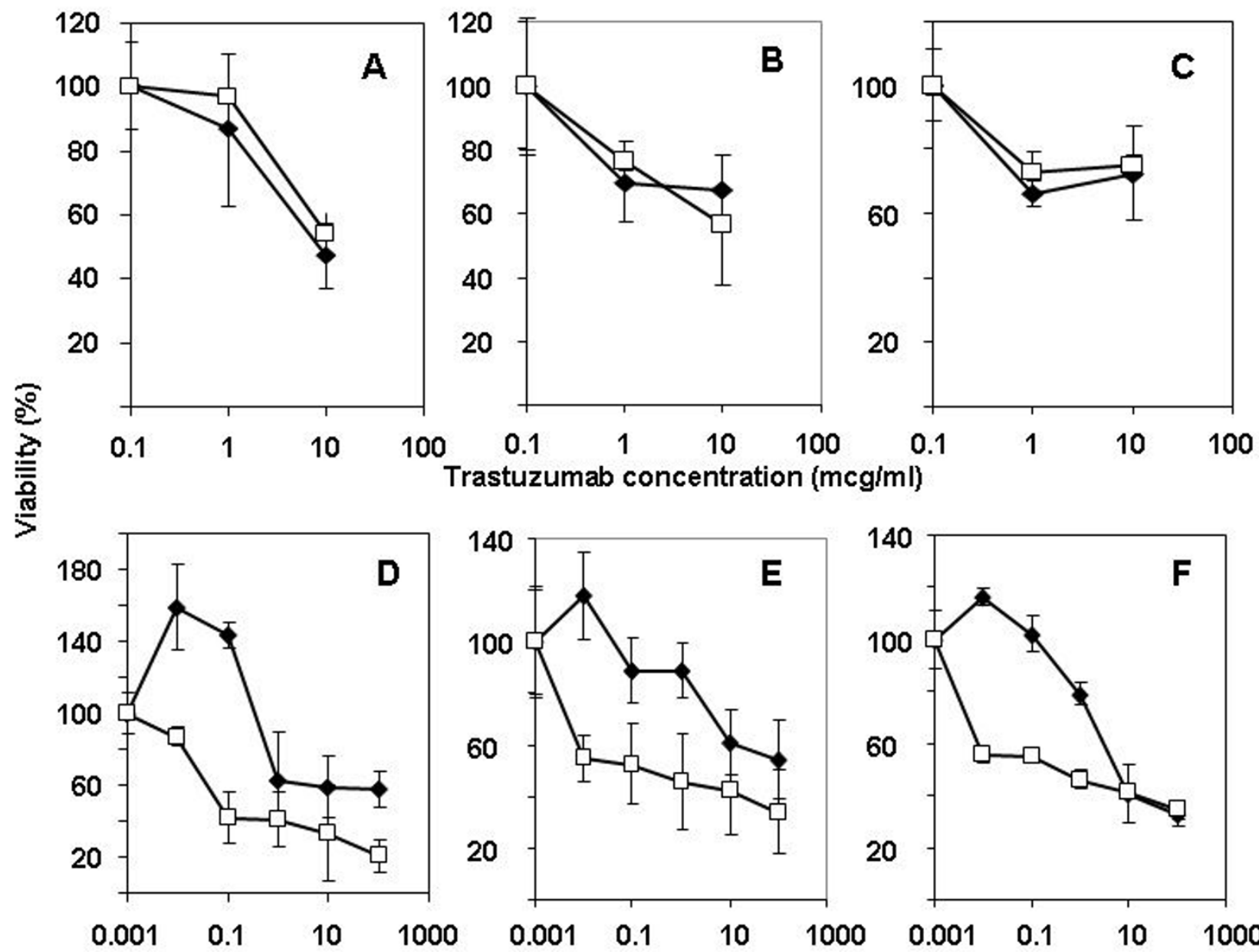

140

100

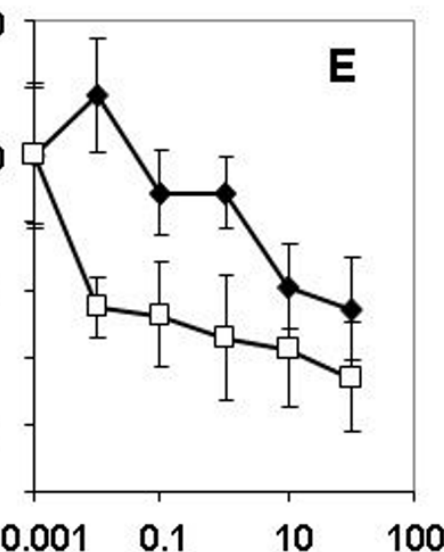

140

100

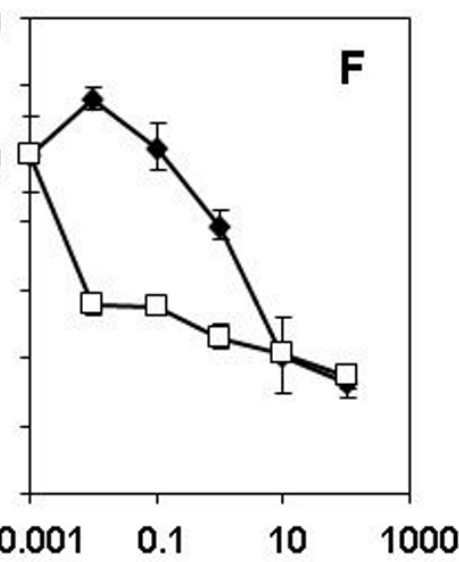

Rapamycin concentration (nM)

Figure 3

Pin I depletion sensitizes erbB2-amplified cells to Rapamycin but not to Trastuzumab treatments. SKBR3 cells (A, D), BT474 cells (B, E) and AU565 cells (C, F) were transfected with control RNAi (dark symbols) or Pin I siRNA (open symbols), and seeded on day 3 after transfection at 5000 cells/well in 96-well plates, and treated with the indicated concentrations of Rapamycin or Trastuzumab. Cells were allowed to grow for 5 days and the resulting cultures were subjected to an MTT-based viability assay and read in a 96 well reader. Assays were done in triplicates.

decrease in erbB2 levels, while Actin levels stayed unaffected. The effect of Pin1-inhibition on Her2 levels was not only seen in immunoblots but also on the single-cell level using immunofluorescence (Fig. 4A). In AU565 and BT474 cells, the Pin1 stain is a diffuse nuclear and cytoplasmic stain (red) while the Her2 stain encircles the cytoplasmic membrane (green). After Pin1 inhibition (lower panel), the Her2 stain is only a scant membrane and cytoplasmic stain (Fig. 4A). DAPI stain was used to visualize the nuclei. To ensure that our findings were not an off-target effect of the siRNA, we used alternate Pin 1 siRNAs as well as over-expression of a dominant-negative mutant of Pin1 (Pin1 S16A, [13]), and, using this alternate mechanism to suppress Pin1's function, we saw again a decrease in erbB2 levels when the Pin1S16A mutant was overexpressed (Fig. 4C).

\section{Pin I inhibition leads to decreased Her2 levels through a post-transcriptional mechanism}

Her2's function is thought to be regulated primarily through tyrosine phosphorylation, while Her2 protein levels are regulated by transcriptional mechanisms [37] as well as by proteasome-mediated degradation $[38,39]$. Pin1-mediated prolyl isomerization regulates proteasomal degradation of some of its target proteins, such as the degradation of c-myc[40] and Cyclin E[41], and prevention of degradation of cyclin D1 $[14,25]$. However, a regulatory role of Pin 1 for a receptor tyrosine kinase such as 


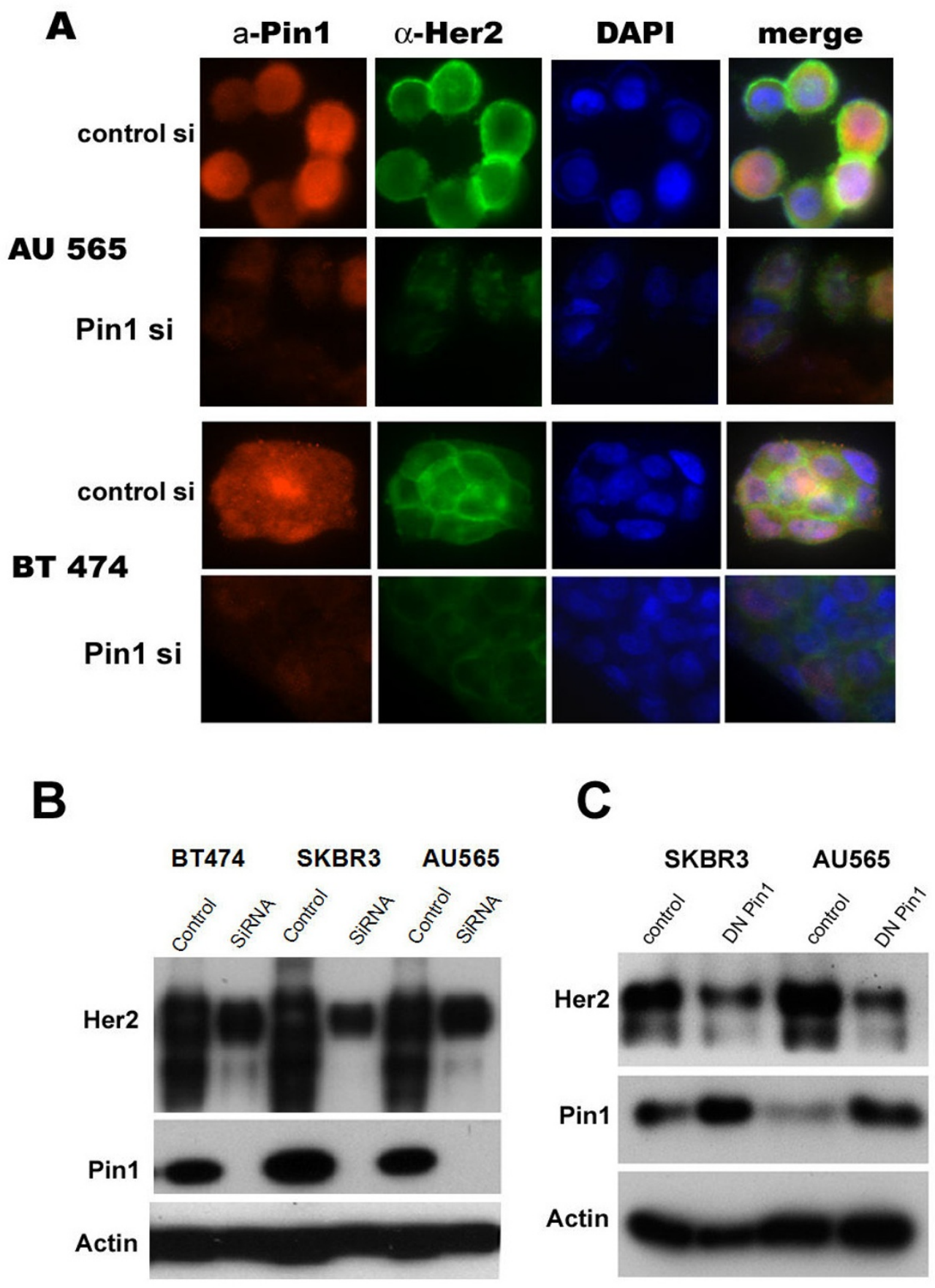

\section{Figure 4}

Pin I inhibition leads to the down-regulation of erbB2. A. Immunofluorescence of BT474 or AU565 cells stained with anti-Pin I (red), anti Her2 (green) and nuclear DAPI stain, and a merged image. Cells were analyzed with a Zeiss Confocal Microscope 3 days after transfection of either control or Pin I siRNA. B, C Immunoblotting of Her2 in cells transfected with Pin I siRNA or control siRNA (B), or dominant-negative Pin I (SI6A mutation) or control vector (C). Actin levels (lower panel) remained stable while Pin I levels decreased in response to siRNA treatment (B, middle panel) or increased after DN Pin I expression (C, middle panel). Her2 levels decreased both in response to Pin I siRNA treatment (B, upper panel) and in response to expression of DN Pin I (C, upper panel). Cells were transfected with either vector or the mutant, and lysates collected for immunoblotting 72 hrs later. 
A

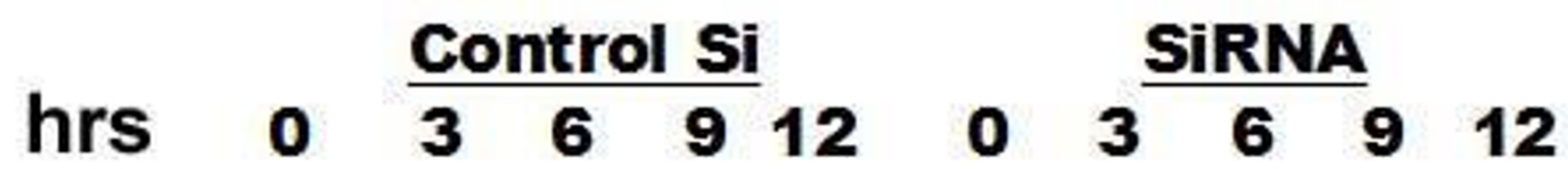

Her2

\section{Actin}

Pin1

B

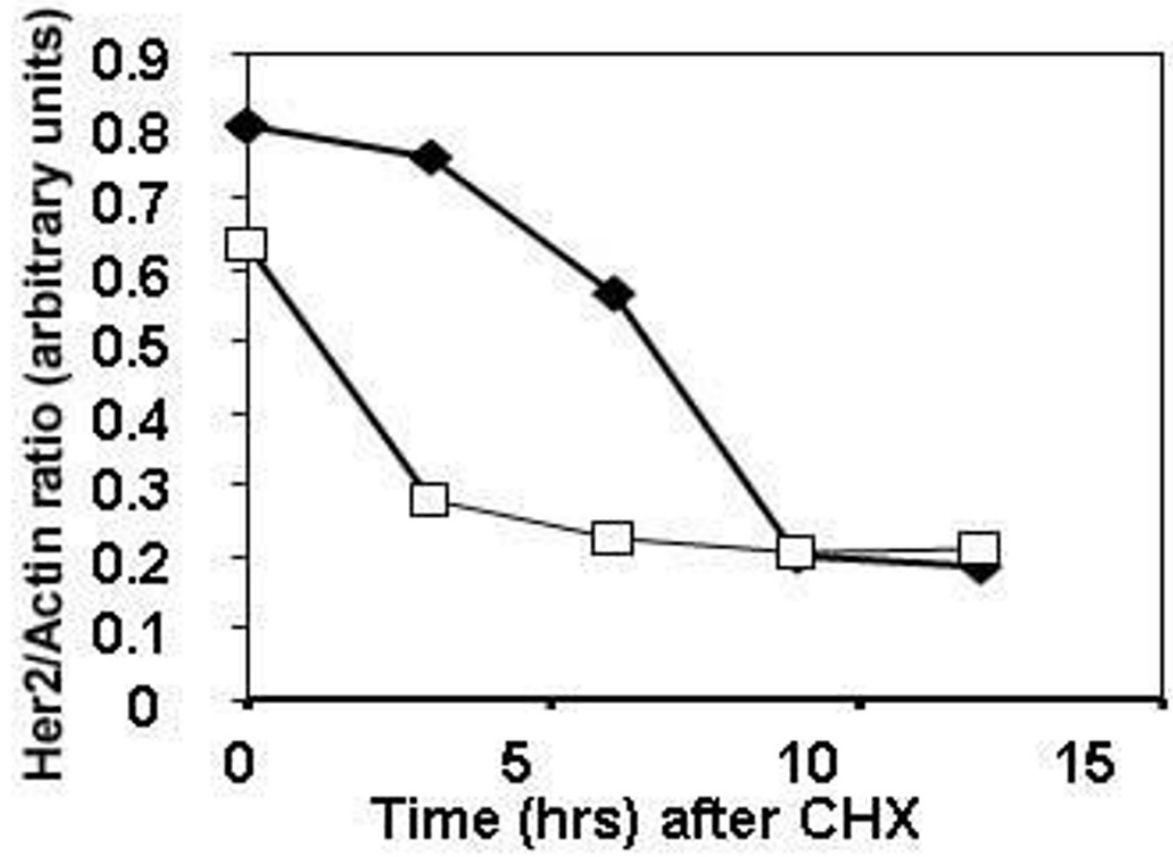

Figure 5

Decreased stability of Her2 after Pin I inhibition. Her2-positive breast cancer cells (SKBR3) were treated with Pin I control or siRNA for 3 days, and then treated with Cycloheximide at $100 \mathrm{mcg} / \mathrm{ml}$, and lysates were obtained at the indicated time points and prepared for immunoblotting (A, B). B The intensity of the bands was quantified using Imagej software and plotted as time versus ratio of Her2/Actin intensity for SKBR3. 
A

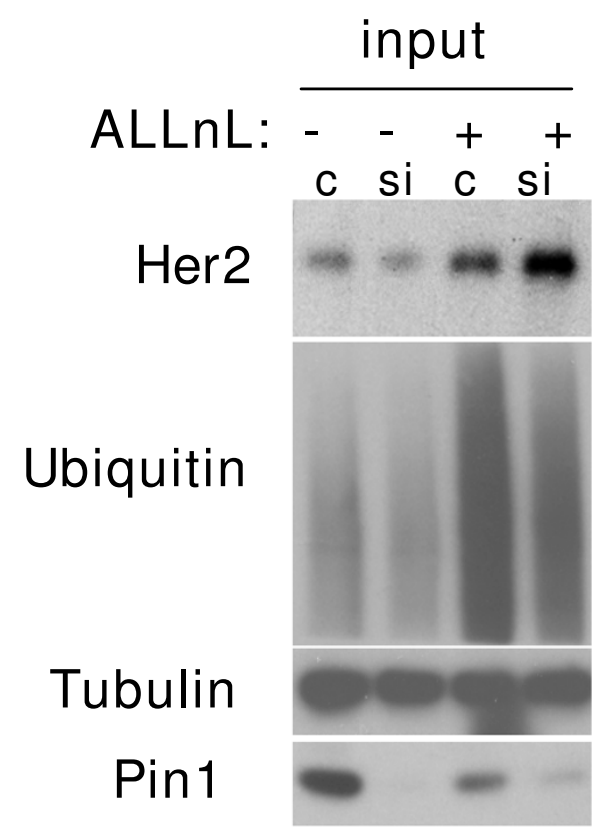

B

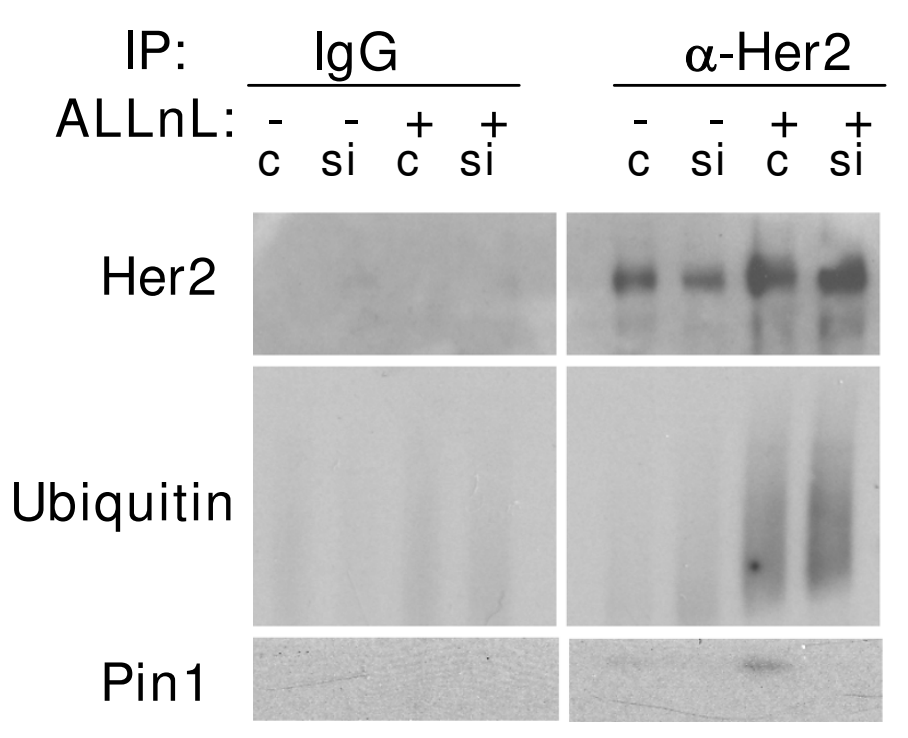

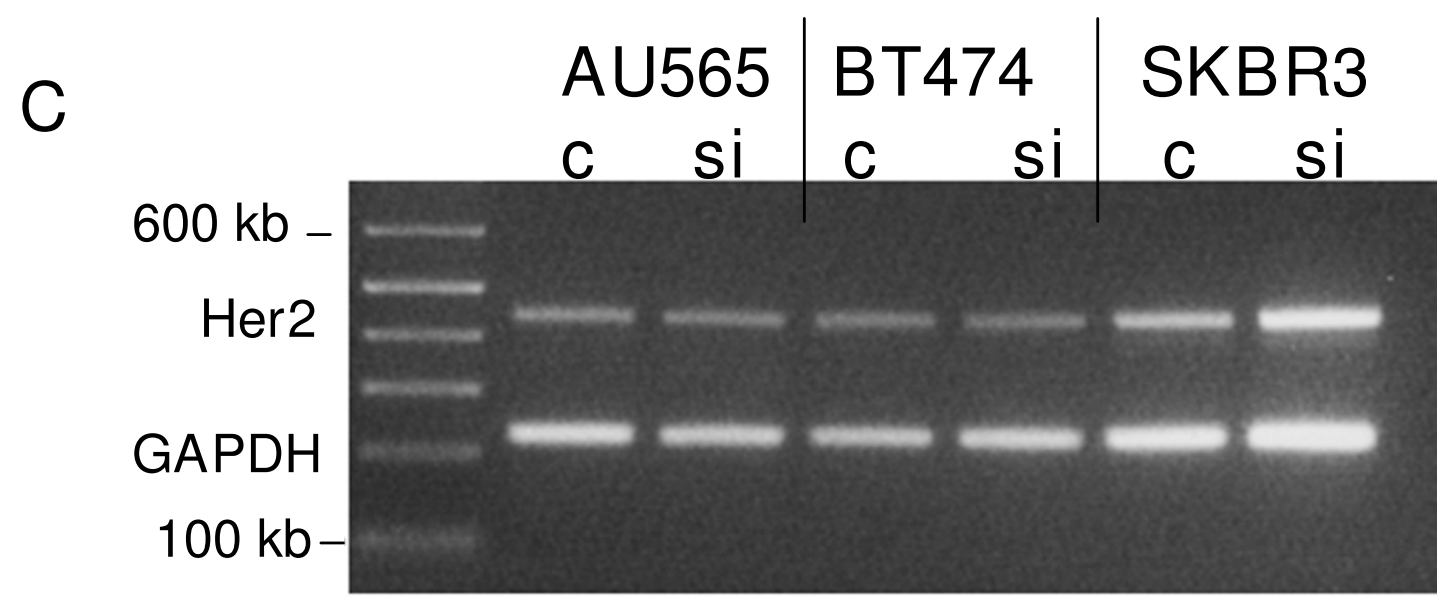

\section{Figure 6}

ErbB2 degradation induced by Pin I inhibition can be rescued by proteasome inhibition. A. SKBR3 cells were transfected with control or Pin I siRNA for 72 hours. 6 hours prior to protein lysis cells were treated with $100 \mu M$ ALLnL. B. Cell lysates were immunoprecipitated with anti-erbB2 antibodies and immunoblotting was done using antibodies against erbB2, Ubiquitin, Tubulin and Pin I. C. SKBR3, AU565 and BT474 were transfected with control or Pin I siRNA for 72 hours. RNA was extracted using Trizol reagent and RT-PCR was performed using erbB2 and GAPDH specific primers.

erbB2 has thus far not been reported. Therefore, we examined if Pin1 inhibition affected the stability of erbB2. In cells treated with control and with Pin1 siRNA inhibition, we followed erbB2 levels after inhibition of protein biosynthesis with Cycloheximide (Fig. 5A, B). As reported earlier [38], erbB2 levels in breast cancer cells treated with
Cycloheximide started to decrease within 3 to 6 hours of Cycloheximide treatment, and continued to drop after 9 hours [38]. ErbB2 levels before Cycloheximide treatment were already lowered because of Pin 1 siRNA treatment in SKBR3 (Fig. 5A) and AU565 and BT474 (not shown). However, in Pin1 siRNA-treated SKBR3 cells where erbB2 
was still detectable after Pin1 siRNA treatment, (Fig. 5A, B), erbB2 levels decreased precipitously within 3 hours after Cycloheximide treatment, indicating an accelerated degradation of erbB2 in the absence of Pin 1.

To determine how Pin 1 depletion accelerated erbB2 degradation, we examined the ubiquitination of erbB2. We used the proteasome inhibitor ALLnL to stabilize ubiquitinated erbB2 for 6 hours prior to lysis of the cells. As expected, the levels of erbB2 and of ubiquitination increased substantially after treatment with the proteasome inhibitor (Fig. 6A). In co-immunoprecipitation with erbB2 antibodies we found that the increase in erbB2 is indeed accompanied by an increase in erbB2 ubiquitination (Fig. 6B). Interestingly, we found that ALLnL treatment prevented the ubiquitin-mediated degradation of erbB2 induced by Pin 1 depletion (Fig. 6), and that Pin1 itself co-precipitated with the protein complexes that contain ubiquitinated erbB2 (Fig. 6B). Finally, we asked if Pin1 inhibition affected erbB2 mRNA levels (Fig. 6C). We used a semi-quantitative RT-PCR approach, and found that erbB2 transcription did not differ in control and Pin 1 siRNA-treated cells. In summary, our data suggest that Pin 1 regulates erbB2 stability by interfering with its proteasomal degradation.

\section{Discussion}

Her2-positive breast cancer presents a special clinical problem as the amplification of Her2 on the one hand is a clear indicator of poor prognosis, while on the other hand it is also a clear predictor of response to Her2directed therapies [42]. The humanized monoclonal antibody trastuzumab (Herceptin) is initially clearly effective as mono- and in combination treatments. However, almost all patients develop resistance and the disease eventually progresses on trastuzumab [42], making the development of strategies to overcome Trastuzumab resistance urgent. To evaluate Pin 1 as a potential treatment target for Her2+ breast cancer, we set out first to examine the prevalence of Pin 1 expression in Her2-positive breast cancer, and found co-expression in $62 \%$ of Her2+ breast cancer specimen, suggesting that simultaneous inhibition of Pin 1 and Her2 might be effective (Fig. 1, Tab 1). Consistently, all three Her2+ cell lines that we examined, were strongly inhibited in their growth by Pin 1 inhibition (Fig. 2).

We had previously shown that Pin 1 -/- mice are largely protected from the tumorigenic effects of oncogenic c-Neu or v-Ha-Ras, but not c-Myc [13], as is the case for cyclin D1 null mice [26], and that Pin 1 ablation is effective in preventing oncogenic Neu or Ras from inducing cyclin D1 in mice [13]. These data confirmed the dependence of Her2induced tumor growth on cyclin D1 phosphorylation [43] and the decisive modulatory role that Pin 1 plays in the regulation of this signaling cascade $[8,13,14,25]$. It is important to note, however, that in the mouse model, we showed that Pin 1 ablation prevented breast cancer [13], while in the current experiments we attempted to inhibit the growth of actual cancer cells. We used Pin 1 siRNA inhibition to down-regulate Pin1 in Her2-positive breast cancer cells. The down-regulation was achieved within 72 hours, and lasted at least for seven days. Because of these kinetics, the siRNA inhibition likely mimics a pharmacological inhibition of Pin 1 better than the genetic absence of Pin1, and our results indicate that siRNA inhibition of Pin 1 is highly effective in inhibiting tumor cell growth of Her2+ breast cancer cells (Fig. 2).

Recent work on the mechanism of trastuzumab-mediated growth arrest and on trastuzumab resistance has shown that in tumors that are trastuzumab-resistant, direct inhibition of one or several of downstream targets of Her2 may help to overcome resistance [44]. The serine/threonine kinase mTOR (mammalian Target of Rapamycin) is a key integrator of multiple cell stimuli, such as growth factor and cytokine signals, but also nutrient and energy status. Furthermore, signals emanating from mTOR regulate cell growth, proliferation and survival $[31,45]$. Inhibition of the mTOR pathway is effective in inhibiting tumor growth in cell lines [46] (Fig. 3) and in xenograft models of erbB2-overexpressing breast cancer [47] and is currently under investigation in clinical trials. Consistently, both, Trastuzumab and the mTOR-inhibitor Rapamycin, inhibited the growth of Her+breast cancer cell lines. Interestingly, we found that simultaneous Pin 1 inhibition increased the sensitivity of these cells to Rapamycin (Fig. $3)$. The sensitization of Her+ breast cancer cells to Rapamycin by Pin-inhibition was expected as Pin1 regulates signaling both up- and downstream from mTOR, thereby likely rendering these cells more vulnerable to growth arrest as a consequence of Pin 1 inhibition. On the other hand, Pin1 inhibition did not increase the sensitivity of these cells to Trastuzumab. This may be explained by our finding that Pin 1 induces the degradation of erbB2, thereby reducing the levels of the Trastuzumab binding sites (Fig. 4, 5).

Our data indicate that Pin 1 is a binding partner of the erbB2 protein complex, and that erbB2 degradation induced by Pin 1 inhibition can be rescued by proteasome inhibition (Fig. 6). There is precedent for the interaction of Pin 1 with proteins that subsequently undergo ubiquitin-mediated degradation: The interaction of Pin 1 with p53 protects phosphorylated p53 from interaction with its ubiquitin ligase, MDM2 $[48,49]$ and Pin 1 's interaction with the transcriptional activator Che1 [50], which promotes interaction with HDM2 and subsequent degradation of Che1. Pin1's exact binding site in the erbB2 protein complex is yet to be determined. The amount of 
Pin 1 that co-immunoprecipitated increased substantially when we prevented proteasome-mediated degradation of erbB2 that led to the accumulation of ubiquitinated erbB2. These findings strongly support a role of Pin1 for the protein stabilization of erbB2. Threonine or Serine phosphorylation has only recently been found to occur in erbB2 in response to phorbol-ester or growth factor treatment $[51,52]$. The effects of threonine or serine phosphorylation on the function or stability of ErbB2 are largely unknown. Two putative phosphorylation sites are flanked by a proline, and they are therefore potential Pin 1 binding sites, Threonine 701 and Serine 1174. We are currently investigating if Pin1-mediated prolyl-isomerization at T701 and/or S1174 could affect the ubiquitination of erbB2, its kinase activity or its ability to assemble with the triage complex erbB2-CHIP-HSP90-HSP70 [39]. It is also possible that Pin1 affects erbB2 stability not through direct interaction but indirectly through modulation of the respective Ubiquitin-ligase or some other modification of the proteasome complex.

The development of Prolyl-isomerase inhibitors as cancer therapeutics is still at an early stage. The only inhibitors of prolyl isomerization currently in clinical trials are the mTOR inhibitors. These Rapamycin analogs are direct inhibitors of the prolyl isomerase FKBP12 [31,53], which then inhibits mTOR, and are in clinical trials in kidney, breast and lung cancer $[47,54]$. Pin 1 itself has been proposed as a potential therapeutic target, but aside from Juglone $[55,56]$, specific inhibitors have to date not yet been identified. Knowing which tumors express Pin1 highly and therefore are "Pin1-inhibitor-sensitive" may help assess, which tumor types might respond to Pin1directed treatments. For therapeutic purposes, the diversity of signaling cascades that Pin 1 is involved in may be an advantage and provide the broad inhibitory coverage of targets that may be needed to treat cancer efficiently [57]. Our data suggest that inhibition of phospho-specific prolylisomerization by Pin 1 may provide a way of simultaneously blocking multiple signal transduction pathways and enhancing the efficacy of specific target-directed medications.

\section{Competing interests}

The authors declare that they have no competing interests.

\section{Authors' contributions}

PBL carried out most of the experiments including the immunohistochemistry and immunofluorescence stains, cell viability assays and immunoblotting in response to treatments and drafted the manuscript. LB and EH participated in cell culture, RT-PCR and immunoblotting experiments. BW read IHC slides. KPL participated in the design of the study and provided critical reagents. GMW conceived of the study, participated in its design and coordi- nation, participated in the experiments and edited the manuscript. The authors read and approved the final manuscript.

\section{Acknowledgements}

This work was funded by K08 CA093655 to GW, a career development award through the Specialized Programs of Research Excellence in Breast Cancer CA089393 from the National Cancer Institute, NIH, Department of Health and Human Services; and a AAR Special Fellowship (P.B.L.).

\section{References}

I. Slamon DJ, Clark GM, Wong SG, Levin WJ, Ullrich A, McGuire WL: Human breast cancer: correlation of relapse and survival with amplification of the HER-2/neu oncogene. Science 1987, 235: $177-182$.

2. Pegram MD, Pauletti G, Slamon DJ: HER-2/neu as a predictive marker of response to breast cancer therapy. Breast Cancer Res Treat 1998, 52:65-77.

3. Pegram MD, Lipton A, Hayes DF, Weber BL, Baselga JM, Tripathy D, Baly D, Baughman SA, Twaddell T, Glaspy JA, Slamon DJ: Phase II study of receptor-enhanced chemosensitivity using recombinant humanized anti-p I 85HER2/neu monoclonal antibody plus cisplatin in patients with HER2/neu-overexpressing metastatic breast cancer refractory to chemotherapy treatment. J Clin Oncol 1998, I 6:2659-267I.

4. Wang K, Ma Q, Ren Y, He J, Zhang Y, Chen W: Geldanamycin destabilizes HER2 tyrosine kinase and suppresses Wnt/betacatenin signaling in HER2 overexpressing human breast cancer cells. Oncol Rep 2007, I 7:89-96.

5. Xu W, Yuan X, Beebe K, Xiang Z, Neckers L: Loss of Hsp90 association up-regulates Src-dependent ErbB2 activity. Mol Cell Biol 2007, 27:220-228.

6. Lu PJ, Zhou XZ, Liou YC, Noel JP, Lu KP: Critical role of WW domain phosphorylation in regulating phosphoserine binding activity and Pin I function. J Biol Chem 2002, 277:238I-2384.

7. Wulf G, Finn G, Suizu F, Lu KP: Phosphorylation-specific prolyl isomerization: is there an underlying theme? Nat Cell Biol 2005, 7:435-44I.

8. Wulf GM, Ryo A, Wulf GG, Lee SW, Niu T, Petkova V, Lu KP: Pin I is overexpressed in breast cancer and cooperates with Ras signaling in increasing the transcriptional activity of c-Jun towards cyclin DI. Embo J 200I, 20:3459-3472.

9. Ryo A, Nakamura M, Wulf G, Liou YC, Lu KP: Pin I regulates turnover and subcellular localization of beta-catenin by inhibiting its interaction with APC. Nat Cell Biol 200I, 3:793-80I.

10. Ayala G, Wang D, Wulf G, Frolov A, Li R, Sowadski J, Wheeler TM, Lu KP, Bao L: The prolyl isomerase Pin I is a novel prognostic marker in human prostate cancer. Cancer Res 2003, 63:6244-625I.

II. Bao L, Kimzey A, Sauter G, Sowadski JM, Lu KP, Wang DG: Prevalent overexpression of prolyl isomerase Pin I in human cancers. Am J Pathol 2004, 164: 1727-1737.

12. Ryo A, Uemura $H$, Ishiguro $H$, Saitoh T, Yamaguchi A, Perrem K, Kubota Y, Lu KP, Aoki I: Stable suppression of tumorigenicity by Pin I-targeted RNA interference in prostate cancer. Clin Cancer Res 2005, I I:7523-7531.

13. Wulf G, Garg P, Liou YC, Iglehart D, Lu KP: Modeling breast cancer in vivo and ex vivo reveals an essential role of Pin I in tumorigenesis. Embo J 2004, 23:3397-3407.

14. Liou YC, Ryo A, Huang HK, Lu PJ, Bronson R, Fujimori F, Uchida T, Hunter T, Lu KP: Loss of Pin I function in the mouse causes phenotypes resembling cyclin DI-null phenotypes. Proc Natl Acad Sci USA 2002, 99:। 335-1340.

15. Dougherty MK, Muller J, Ritt DA, Zhou M, Zhou XZ, Copeland TD, Conrads TP, Veenstra TD, Lu KP, Morrison DK: Regulation of RafI by direct feedback phosphorylation. Mol Cell 2005, I 7:2 I 5-224.

16. Monje P, Hernandez-Losa J, Lyons RJ, Castellone MD, Gutkind JS: Regulation of the transcriptional activity of c-Fos by ERK. A novel role for the prolyl isomerase PINI. J Biol Chem 2005, 280:3508I-35084. 
17. Gao M, Labuda T, Xia Y, Gallagher E, Fang D, Liu YC, Karin M: Jun turnover is controlled through JNK-dependent phosphorylation of the E3 ligase Itch. Science 2004, 306:27I-275.

18. Miyashita $\mathrm{H}$, Mori S, Motegi K, Fukumoto M, Uchida T: Pin I is overexpressed in oral squamous cell carcinoma and its levels correlate with cyclin DI overexpression. Oncol Rep 2003, 10:455-461.

19. Miyashita H, Uchida T, Mori S, Echigo S, Motegi K: Expression status of Pin I and cyclins in oral squamous cell carcinoma: Pin I correlates with Cyclin DI mRNA expression and clinical significance of cyclins. Oncol Rep 2003, I 0: I045-1048.

20. Li H, Wang S, Zhu T, Zhou J, Xu Q, Lu Y, Ma D: Pin I contributes to cervical tumorigenesis by regulating cyclin $\mathrm{DI}$ expression. Oncol Rep 2006, 16:491-496.

21. Lu KP, Hanes SD, Hunter T: A human peptidyl-prolyl isomerase essential for regulation of mitosis. Nature 1996, 380:544-547.

22. Kurebayashi J: Biological and clinical significance of HER2 overexpression in breast cancer. Breast Cancer 200I, 8:45-5I.

23. Harari $D$, Yarden $Y$ : Molecular mechanisms underlying ErbB2/ HER2 action in breast cancer. Oncogene 2000, 19:6|02-6I|4

24. Carter P, Presta L, Gorman CM, Ridgway JB, Henner D, Wong WL, Rowland AM, Kotts C, Carver ME, Shepard HM: Humanization of an anti-p | 85HER2 antibody for human cancer therapy. Proc Natl Acad Sci USA 1992, 89:4285-4289.

25. Ryo A, Liou YC, Wulf G, Nakamura M, Lee SW, Lu KP: PINI is an E2F target gene essential for Neu/Ras-induced transformation of mammary epithelial cells. Mol Cell Biol 2002, 22:528I-5295.

26. Yu Q, Geng Y, Sicinski P: Specific protection against breast cancers by cyclin DI ablation. Nature 200I, 4 I I:I017-102I.

27. Hsu T, McRackan D, Vincent TS, Gert de Couet H: Drosophila Pin I prolyl isomerase Dodo is a MAP kinase signal responder during oogenesis. Nat Cell Biol 200I, 3:538-543.

28. Tripathy D, Slamon DJ, Cobleigh M, Arnold A, Saleh M, Mortimer JE Murphy M, Stewart SJ: Safety of treatment of metastatic breast cancer with trastuzumab beyond disease progression. J Clin Oncol 2004, 22: 1063-1070.

29. Nagata Y, Lan KH, Zhou X, Tan M, Esteva FJ, Sahin AA, Klos KS, Li P, Monia BP, Nguyen NT, Hortobagyi GN, Hung MC, Yu D: PTEN activation contributes to tumor inhibition by trastuzumab, and loss of PTEN predicts trastuzumab resistance in patients. Cancer Cell 2004, 6: I I 7-I 27.

30. Slamon D, Pegram M: Rationale for trastuzumab (Herceptin) in adjuvant breast cancer trials. Semin Oncol 2001, 28:13-19.

31. Hidalgo M, Rowinsky EK: The rapamycin-sensitive signal transduction pathway as a target for cancer therapy. Oncogene 2000, 19:6680-6686.

32. Luan FL, Hojo M, Maluccio M, Yamaji K, Suthanthiran M: Rapamycin blocks tumor progression: unlinking immunosuppression from antitumor efficacy. Transplantation 2002, 73:1565-1572.

33. Nagy P, Friedlander E, Tanner M, Kapanen Al, Carraway KL, Isola J, Jovin TM: Decreased accessibility and lack of activation of ErbB2 in JIMT-I, a herceptin-resistant, MUC4-expressing breast cancer cell line. Cancer Res 2005, 65:473-482.

34. Cobleigh MA, Vogel CL, Tripathy D, Robert NJ, Scholl S, Fehrenbacher L, Wolter JM, Paton V, Shak S, Lieberman G, Slamon DJ: Multinational study of the efficacy and safety of humanized antiHER2 monoclonal antibody in women who have HER2-overexpressing metastatic breast cancer that has progressed after chemotherapy for metastatic disease. J Clin Oncol 1999, I 7:2639-2648.

35. Pandolfi PP: Breast cancer - loss of PTEN predicts resistance to treatment. N Engl J Med 2004, 35 I:2337-2338.

36. Mosley JD, Poirier JT, Seachrist DD, Landis MD, Keri RA: Rapamycin inhibits multiple stages of c-Neu/ErbB2 induced tumor progression in a transgenic mouse model of HER2-positive breast cancer. Mol Cancer Ther 2007, 6:2188-2197.

37. Suen TC, Hung MC: Multiple cis- and trans-acting elements involved in regulation of the neu gene. Mol Cell Biol 1990 10:6306-6315.

38. Mimnaugh EG, Chavany $C$, Neckers L: Polyubiquitination and proteasomal degradation of the $\mathrm{p} / 85 \mathrm{c}$-erbB-2 receptor protein-tyrosine kinase induced by geldanamycin. J Biol Chem 1996, 271:22796-2280I.

39. Xu W, Marcu M, Yuan X, Mimnaugh E, Patterson C, Neckers L: Chaperone-dependent E3 ubiquitin ligase CHIP mediates a degradative pathway for c-ErbB2/Neu. Proc Natl Acad Sci USA 2002, 99: I 2847-I 2852.

40. Yeh E, Cunningham M, Arnold H, Chasse D, Monteith T, Ivaldi G, Hahn WC, Stukenberg PT, Shenolikar S, Uchida T, Counter CM, Nevins JR, Means AR, Sears R: A signalling pathway controlling cMyc degradation that impacts oncogenic transformation of human cells. Nat Cell Biol 2004, 6:308-3I8.

4I. Yeh ES, Lew BO, Means AR: The loss of PINI deregulates cyclin $E$ and sensitizes mouse embryo fibroblasts to genomic instability. J Biol Chem 2006, 28 I:24I-25 I.

42. Slamon DJ, Leyland-Jones B, Shak S, Fuchs H, Paton V, Bajamonde A, Fleming T, Eiermann W, Wolter J, Pegram M, Baselga J, Norton L: Use of chemotherapy plus a monoclonal antibody against HER2 for metastatic breast cancer that overexpresses HER2. N Engl J Med 200I, 344:783-792.

43. Hulit J, Lee RJ, Russell RG, Pestell RG: ErbB-2-induced mammary tumor growth: the role of cyclin DI and p27Kipl. Biochem Pharmacol 2002, 64:827-836.

44. Park BH, Davidson NE: PI3 kinase activation and response to Trastuzumab Therapy: what's neu with herceptin resistance? Cancer Cell 2007, I 2:297-299.

45. Martin KA, Blenis J: Coordinate regulation of translation by the PI 3-kinase and mTOR pathways. Adv Cancer Res 2002, 86: I-39.

46. Vazquez-Martin A, Oliveras-Ferraros C, Colomer R, Brunet J, Menendez JA: Low-scale phosphoproteome analyses identify the mTOR effector p70 S6 kinase I as a specific biomarker of the dual-HERI/HER2 tyrosine kinase inhibitor lapatinib (Tykerb(R)) in human breast carcinoma cells. Ann Oncol 2008.

47. Yu K, Toral-Barza L, Discafani C, Zhang WG, Skotnicki J, Frost P, Gibbons J]: $m$ TOR, a novel target in breast cancer: the effect of CCI-779, an mTOR inhibitor, in preclinical models of breast cancer. Endocr Relat Cancer 200I, 8:249-258.

48. Zheng H, You H, Zhou XZ, Murray SA, Uchida T, Wulf G, Gu L, Tang $X$, Lu KP, Xiao $Z X$ : The prolyl isomerase Pin I is a regulator of p53 in genotoxic response. Nature 2002, 419:849-853.

49. Zacchi P, Gostissa M, Uchida T, Salvagno C, Avolio F, Volinia S, Ronai Z, Blandino G, Schneider C, Del Sal G: The prolyl isomerase Pin I reveals a mechanism to control p53 functions after genotoxic insults. Nature 2002, 419:853-857.

50. De Nicola F, Bruno T, lezzi S, Di Padova M, Floridi A, Passananti C Del Sal G, Fanciulli M: The prolyl isomerase Pin I affects CHE-I stability in response to apoptotic DNA damage. J Biol Chem 2007.

5I. Ouyang X, Gulliford T, Huang GC, Harper-Wynne C, Shousha S, Epstein RJ: Multisite phosphotyping of the ErbB-2 oncoprotein in human breast cancer. Mol Diagn 200I, 6:17-25.

52. Ouyang X, Gulliford T, Zhang H, Smith G, Huang G, Epstein RJ: Association of ErbB2 SerlII3 phosphorylation with epidermal growth factor receptor co-expression and poor prognosis in human breast cancer. Mol Cell Biochem 200I, 21 8:47-54.

53. Jordens J, Janssens V, Longin S, Stevens I, Martens E, Bultynck G, Engelborghs Y, Lescrinier E, Waelkens E, Goris J, Van Hoof C: The protein phosphatase $2 \mathrm{~A}$ phosphatase activator is a novel peptidyl-prolyl cis/trans-isomerase. J Biol Chem 2006, 281:6349-6357.

54. Raymond E, Alexandre J, Faivre S, Vera K, Materman E, Boni J, Leister C, Korth-Bradley J, Hanauske A, Armand JP: Safety and pharmacokinetics of escalated doses of weekly intravenous infusion of CCI-779, a novel mTOR inhibitor, in patients with cancer. J Clin Oncol 2004, 22:2336-2347.

55. Albert AL, Lavoie SB, Vincent M: Multisite phosphorylation of Pin I-associated mitotic phosphoproteins revealed by monoclonal antibodies MPM-2 and CC-3. BMC Cell Biol 2004, 5:22.

56. Chao SH, Greenleaf AL, Price DH: Juglone, an inhibitor of the peptidyl-prolyl isomerase PinI, also directly blocks transcription. Nucleic Acids Res 2001, 29:767-773.

57. Petrelli $A$, Giordano S: From single- to multi-target drugs in cancer therapy: when aspecificity becomes an advantage. Curr Med Chem 2008, I 5:422-432. 